\title{
Discovery of Highly Potent and Selective CXCR4 Inhibitors Using Protein Epitope Mimetics (PEM) Technology
}

\author{
Alexander Lederer§a , Steven J. DeMarco a, Heiko Henze ${ }^{a}$, Barbara Romagnolia, Reshmi \\ Mukherjee $^{\mathrm{a}, \mathrm{d}}$, Jürg Zumbrunn ${ }^{\mathrm{a}}$, Federico Brianza ${ }^{\mathrm{a}}$, Frank O. Gombert ${ }^{\mathrm{a}}$, Christian Ludin ${ }^{\mathrm{a}}$, Jan \\ Willem Vrijbloed ${ }^{a}$, Jean-Pierre Obrecht ${ }^{a}$, Sergio Lociuro ${ }^{a}, \mathrm{e}$, Vincent Brondanib ${ }^{b}$, François Hamy ${ }^{b, f}$, \\ Thomas Klimkait ${ }^{b}$, Kerstin Moehle ${ }^{c}$, John A. Robinson ${ }^{c}$ and Daniel Obrecht ${ }^{*}$ a \\ $\S$ METTLER TOLEDO Awards 2006 (Oral Presentation)
}

\begin{abstract}
Novel, highly potent CXCR4 inhibitors with good pharmacokinetic properties were obtained by applying PEM technology starting from the naturally occurring $\beta$-hairpin peptide polyphemusin II. The design involved incorporation of key residues from polyphemusin II into a macrocyclic template-bound $\beta$-hairpin mimetic. Using a parallel synthesis approach, the potency and ADME properties of the mimetics were optimized, resulting in CXCR4 inhibitors such as POL2438 and POL3026. Their activities were confirmed in a series of in vitro HIV-1 infection assays. Besides high selectivity for CXCR4, POL3026 had excellent plasma stability and favorable pharmacokinetic properties in dogs. In a murine model POL3026 was highly efficacious in hematopoietic stem cell mobilization. Hence, PEM-based CXCR4 inhibitors have the potential to become therapeutic agents for the treatment of HIV infections (as entry inhibitor), cancer (e.g. for inhibition of metastasis), stem cell transplant and inflammation.
\end{abstract}

Keywords: CXCR4 inhibitor · Drug design · Peptide $\cdot$ Protein epitope mimetics $\cdot$ Stem cell mobilization

\section{Introduction}

Today's drug discovery efforts focus mainly on two major drug classes: small molecules and biopharmaceuticals. In collaboration with Prof. J. A. Robinson at the University of Zurich, Polyphor has developed a new proprietary technology, known as Protein Epitope Mimetics (PEM). PEM molecules are medium-sized, cyclic peptide-like molecules $(1-2 \mathrm{kDa})$ that mimic secondary structure motifs of proteins, such as the $\beta$-hairpin and the $\alpha$-helix (Fig.

${ }^{*}$ Correspondence: Dr. D. Obrecht ${ }^{\mathrm{a}}$

Tel.: + 41614869898

Fax: + 41614869859

E-Mail: daniel.obrecht@polyphor.com

apolyphor AG, CH-4123 Allschwil

bInPheno AG, CH-4051 Basel

Institute of Organic Chemistry, University of Zurich Winterthurerstrasse 190, $\mathrm{CH}-8057$ Zurich

dPresent address: Harvard Medical School, Boston, MA-02115, USA

ePresent address: Arpida AG, CH-4142 Münchenstein

fPresent address: Institute for Medical Microbiology,

$\mathrm{CH}-4003$ Basel

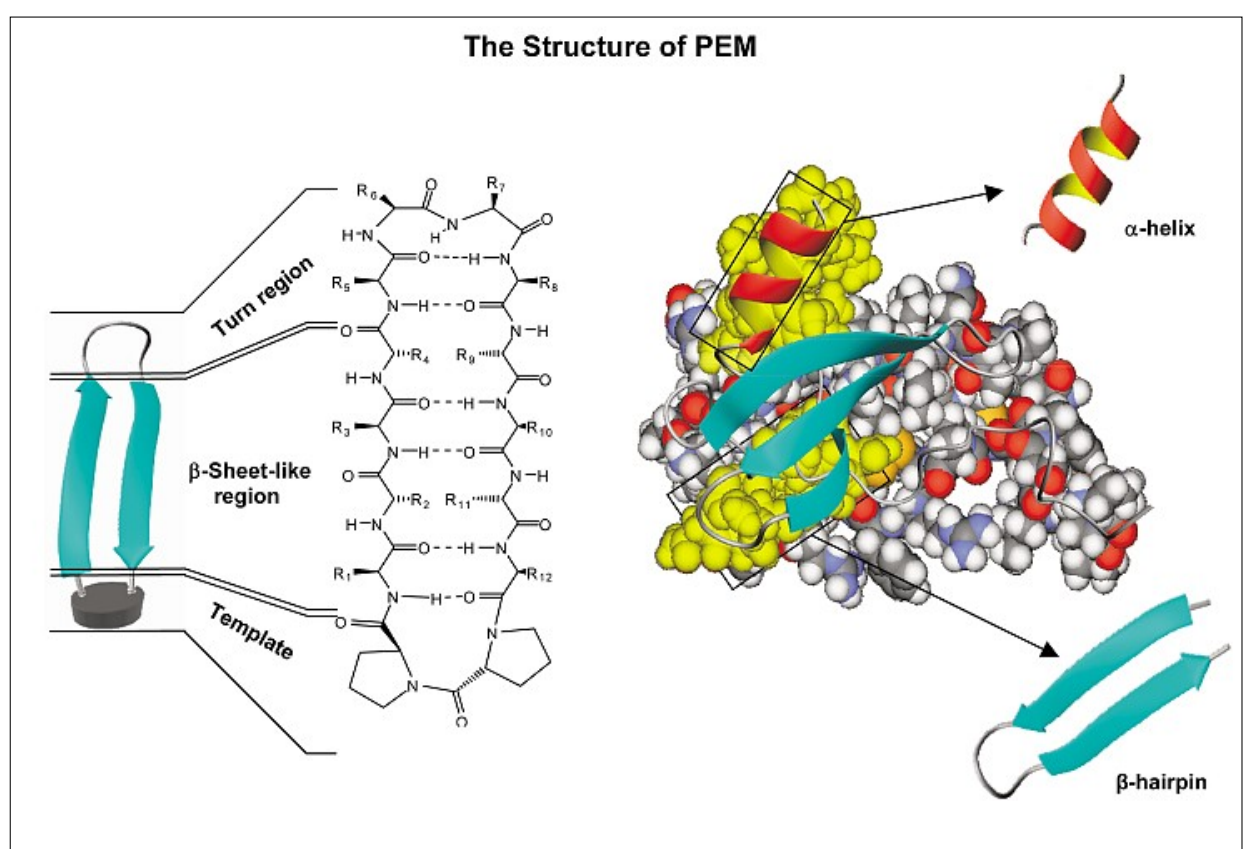

Fig. 1. The $\beta$-hairpin has been shown to be the predominant structural motif in known protein-protein interactions. The left part of the Fig. shows the structure of a PEM molecule in detail.

1). ${ }^{[1]}$ In particular, the $\beta$-hairpin motif is a key structural element involved in many protein-protein interactions of therapeutic relevance. ${ }^{[2]}$ Therefore, PEM molecules lie at the interface of small molecules and bio- pharmaceuticals, and combine several advantages of both established drug classes. Structurally they can be best compared to natural product drugs such as cyclosporin, vancomycin or daptomycin. ${ }^{[3]}$ 


\section{PEM Technology}

PEM molecules consist of a $\beta$-hairpinshaped, cyclic peptide chain which is stabilized by a $\beta$-turn inducing template. The template induces and stabilizes the crucial intramolecular $\mathrm{H}$-bond network observed in $\beta$-hairpins and facilitates cyclization (Fig. 1). PEM molecules can be efficiently synthesized by solid phase synthesis in a 96-parallel format. They offer many possibilities for structural variation in order to modulate activity, selectivity and ADME properties. In general, PEM molecules comprise 4 to 20 natural or non-natural amino acids, however, building blocks like amino acid isosteres can also be incorporated. Besides the most convenient D-Pro-L-Protemplate, several other structurally more complex templates are at our disposal. ${ }^{[4]}$

\section{PEM Design}

The design of an initial PEM library depends on the available target-related structural information. The following approaches can be envisaged:

i) If only the sequence of the ligand is known, a PEM sequence scanning approach can be taken.

ii) Key residues of the ligand and/or receptor (identified e.g. by site-directed mutagenesis studies), can be incorporated into PEM design (conformational scanning).

iii) As shown below, active sequences from $\beta$-hairpin-shaped natural products and phage display are a rich source of structural information for the design of PEM libraries. [5]

iv) Finally, structural data from X-ray or NMR of the ligand, preferably bound to the receptor, can be an excellent starting point for the design of PEM libraries. ${ }^{[6]}$

\section{The Chemokine Receptor CXCR4}

The chemokine receptor CXCR4 is a cell surface receptor belonging to the G-protein coupled receptor (GPCR) superfamily. ${ }^{[7]}$ The natural ligand of human CXCR4 is stromalderived factor alpha (SDF-1 $\alpha$ ) also known as CXCL12. The CXCR4-SDF- $1 \alpha$ axis is a master regulator of chemotactic cell trafficking in the human body ${ }^{[8]}$ (Fig. 2) and plays a major role in the retention of hematopoietic stem cells in the bone marrow. ${ }^{[9]}$ In addition, it is known that CXCR4 is involved in metastasis of various types of cancer cells to organs overexpressing SDF-1 $\alpha .{ }^{[10]}$ CXCR4 also acts as a co-receptor for the entry of Ttropic HIV-1 into T-cells. ${ }^{[1]}$ Another chemokine receptor, CCR5, acts also as a co-receptor for HIV-1, but only for the cellular entry of M-tropic HIV-1 into macrophages. ${ }^{[12]}$

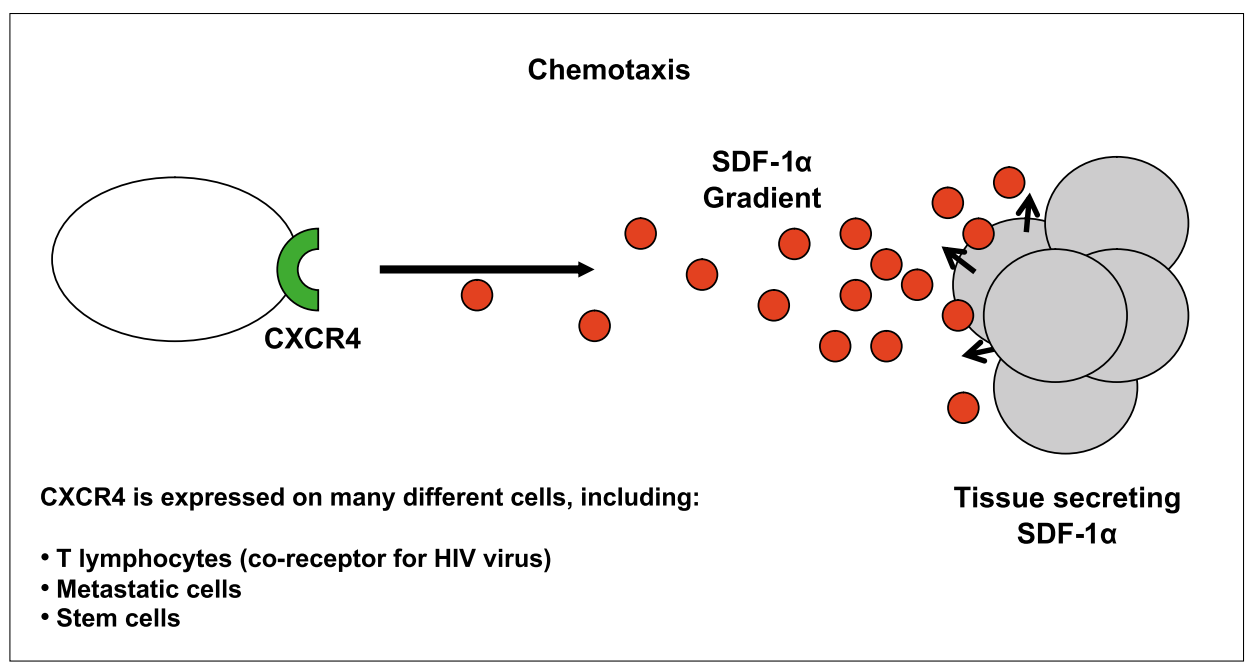

Fig. 2. SDF-1 $\alpha$ is inducing direct positive chemotaxis. Hence, cells bearing CXCR4 direct their movements to a higher concentration of SDF- $1 \alpha$.

\section{Design of PEM-based CXCR4 Inhibitors}

American horseshoe crab (Limus polyphemus)

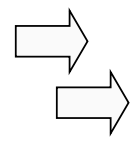

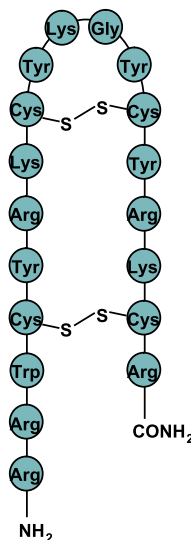

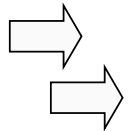

$\beta$-hairpin peptide T22

(Tyr ${ }^{5,12}$, Lys ${ }^{7}$-polyphemusin II)

Fig. 3. The natural product polyphemusin II and the synthetic analogue T22, both twofold disulfidebridged peptides, served as starting point for the design of PEM-based CXCR4 inhibitors.

\section{Therapeutic Applications of CXCR4 Inhibitors}

As the CXCR4-SDF-1 $\alpha$ axis is involved in several important biological processes, CXCR4 inhibitors have potential applications in serious diseases. The inhibition of the SDF- $1 \alpha$ induced chemotaxis results in the mobilization of hematopoietic stem cells from the bone marrow into the blood stream. Currently, mobilized hematopoietic stem cells are the preferred source for autologous or allogeneic transplantation in patients receiving high dose radio- or chemotherapy. Another potential therapeutic application for CXCR4 inhibitors is as anti-metastatic agents for several types of cancers, like breast cancer. It is well known that many cancer cells express CXCR4 and that their migration is directed by SDF- $1 \alpha$.
Hence, it can be anticipated that a CXCR4 inhibitor will lead to a reduction in metastasis of cancer cells.

Finally, CXCR4 inhibitors could find application as entry inhibitors in AIDS therapy.

\section{Design of CXCR4 Inhibitors}

One of the first CXCR4 inhibitors described was polyphemusin II, a naturally occurring 18-amino acid peptide isolated from the American horseshoe crab (Fig. 3). ${ }^{[13]}$ A closely related synthetic analogue described by Nakashima et al. is T22. ${ }^{[14]}$ Investigation of the solution structure by Tamamura and Fujii ${ }^{15]}$ using NMR spectroscopy revealed that T22 adopts a $\beta$-hairpin conformation stabilized by two disul- 
fide bonds. This architecture represented an ideal starting point for the design of CXCR4 inhibitors using PEM Technology. First, we translated the sequence of T22 into a PEM molecule. After several rounds of optimization, a first lead family was obtained showing significantly improved activities and ADME properties, exemplified by POL2438 and POL3026.

\section{Results and Discussion}

Fig. 4 shows the results of two different in vitro assays. The $\mathrm{Ca}^{2+}$ flux assay is a common functional assay for testing GPCR inhibitors. Both Polyphor compounds show $\mathrm{IC}_{50}$ values in the low $\mathrm{nM}$ range, tenfold more potent than TC14011, a truncated synthetic analogue of T22. To our knowledge POL 3026 constitutes the most active CXCR4 inhibitor described to date.

In addition, the inhibition of chemotaxis of CEM cells carrying CXCR4 was assessed. A very low $\mathrm{IMC}_{50}$ of $1.2 \mathrm{nM}$ could be observed. Fig. 4 also summarizes some in vitro $\mathrm{ADME}$ data. The striking increase in plasma stability of POL2438 and POL3026 compared to TC14011 highlights the importance of the cyclic PEM structure for improving both activity and ADME properties. In addition, we did not observe significant metabolism of the compounds by liver enzymes. Encouraged by these promising in vitro ADME data, POL3026 was selected for pharmacokinetic profiling in three male beagle dogs. After subcutaneous administration at a dose level of $1.5 \mathrm{mg} / \mathrm{kg}$ body weight the maximal serum concentration was reached $1 \mathrm{~h}$ after dosing. Then the plasma level decreased with an elimination half-life of $3.4 \mathrm{~h}$. Thus, POL3026 exhibits a good pharmacokinetic profile and smallmolecule-like ADME properties.

The high inhibitory activity was further confirmed in several anti-HIV-tests, among them the deCIPhR assay (Fig. 5). DeCIPhR is a virus replication assay, which can be used to assess entry of different recombinant viruses and derived mutants into CEM-cells. ${ }^{[16]}$ In this assay POL2438 was both highly active and selective in inhibition of T-tropic virus entry. All members of the 'non-sensitive' population were belonging to M-tropic CCR5-using virus strains. This result is in line with the high selectivity of our compounds for CXCR4, and the lack of activity against all other chemokine receptors that we have tested.

Finally, we explored the ability of PEMbased CXCR4 inhibitors to mobilize stem cells in mice. The results of this in vivo efficacy study are shown in Fig. 6. Compared to a well-known CXCR4 inhibitor, one of our most advanced PEM molecules showed a significantly improved efficacy in releasing functional stem cells.

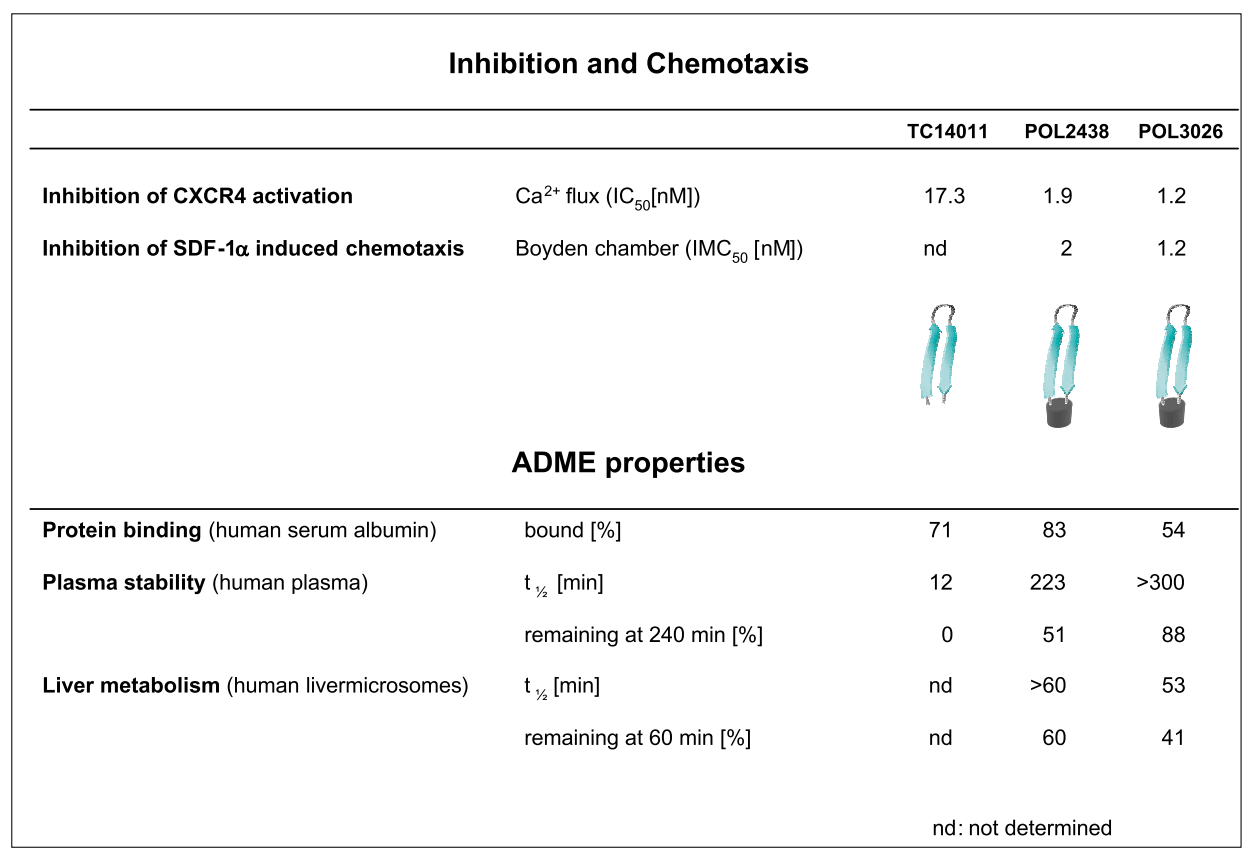

Fig. 4. In vitro proof of concept: Inhibition of CXCR4 activation and SDF-1 $\alpha$ induced chemotaxis of TC 14011, POL2438 and POL3026 as well as selected ADME properties

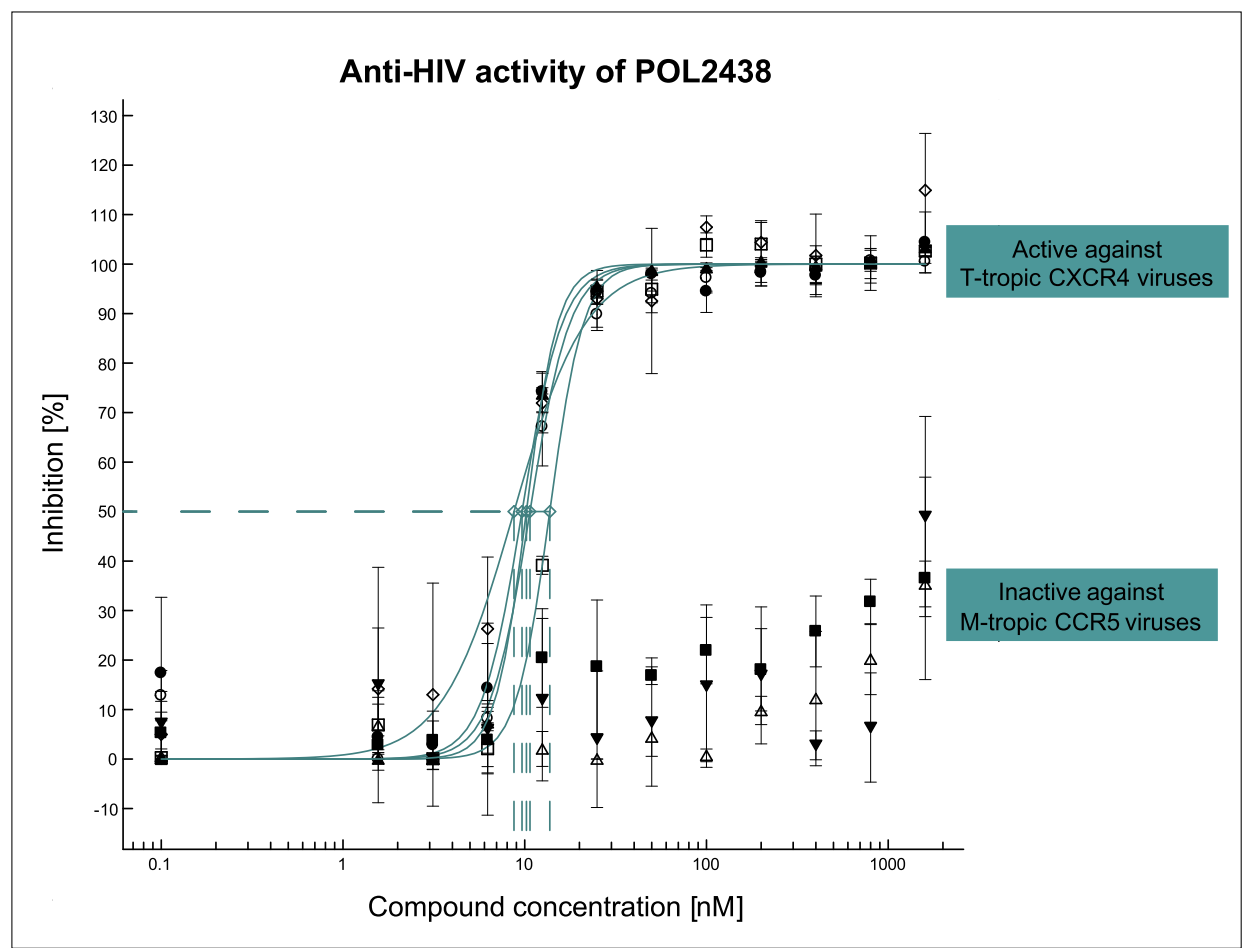

Fig. 5. Anti-HIV activity of POL2438 on HIV clinical variants using the cellular deCIPhR assay. Viral inhibition curves are shown for eight recombinant viruses.

These encouraging in vitro and in vivo results underscore the high potential of PEM-based CXCR4 inhibitors as novel therapeutics in stem cell mobilization, cancer and HIV.

\section{Experimental}

The experimental procedure for the synthesis of our PEM molecules as well as the protocols of the in vitro and in vivo assays have already been reported, ${ }^{[5]}$ except for the in vivo efficacy study of stem cell mobilization which will be published elsewhere.

Received: November 30, 2006

$\overline{[1]}$ a) M. Favre, K. Moehle, L. Jiang, B. Pfeiffer, J. A. Robinson, J. Am. Chem. Soc. 1999, 12, 2679; b) R. Fasan, R. L. Dias, K. Moehle, O. Zerbe, J. W. Vrijbloed, D. Obrecht, J. A. Robinson, Angew. Chem. Int. Ed. 2004, 43, 2109.

[2] a) E. G. Hutchinson, A. Shepherd, J. M. Thornton, Proc. Natl. Acad. Sci. U.S.A. 


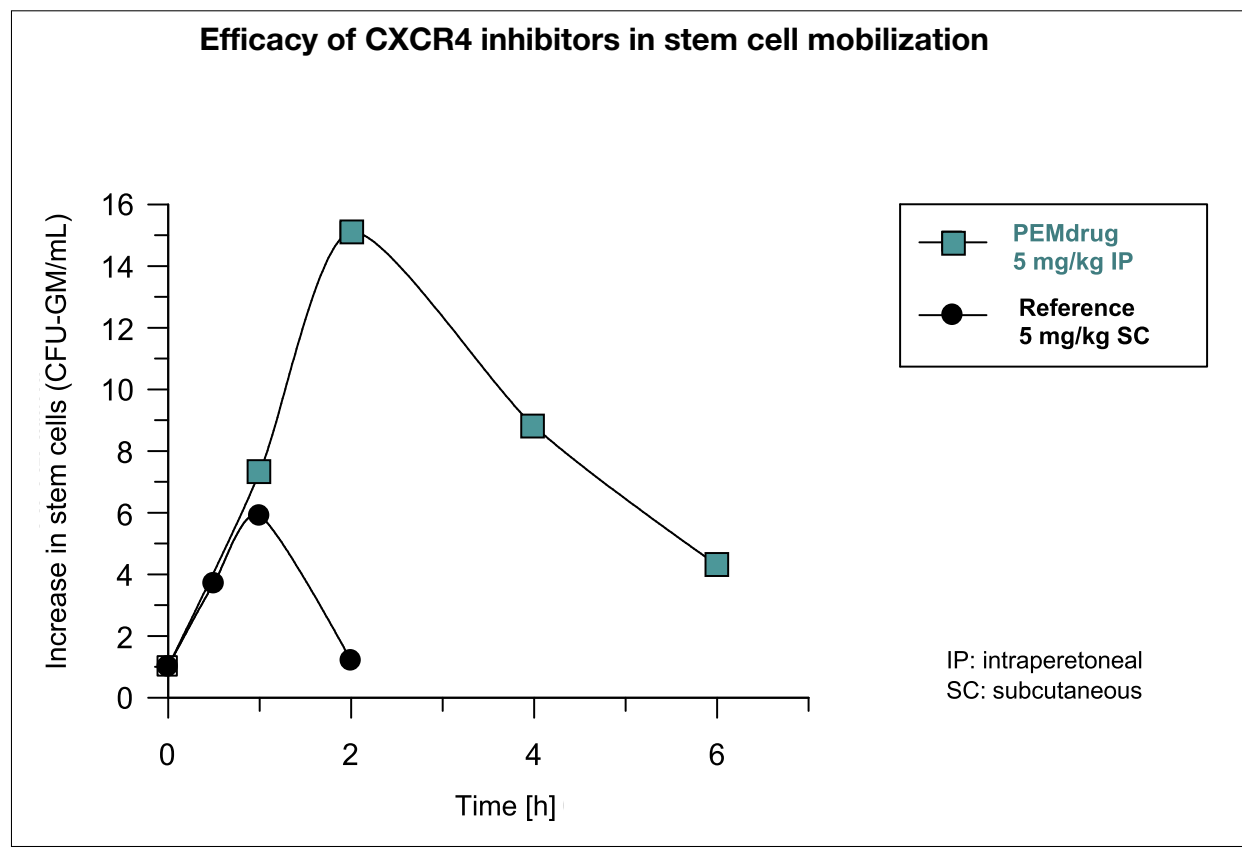

Fig. 6. In vivo proof of concept in the area of stem cell mobilization. The increase in stem cells measured as Colony Forming Units (CFU) of Granulocyte-monocyte progenitors (GM) is depicted as a function of time.

2002, 99, 11157; b) K. Ikeda, O. V. Galzitskaya, H. Nakamura, J. Higo, J. Comput. Chem. 2003, 24, 310.

[3] D. Schwarzer, R. Finking, M. A. Marahiel, Nat. Prod. Rep. 2003, 20, 275.

[4] a) K. Müller, D. Obrecht, A. Knierzinger, C. Stankovic, C. Spiegler, W. Bannwarth, A. Trzeciak, G. Englert, A. M. Labhardt, P. Schönholzer, in 'Perspectives in Medicinal Chemistry', Ed. B. Testa, E. Kyburz, W. Fuhrer, R. Giger, Helvetica Chimica Acta, Basel, 1992, p. 513; b) D. Obrecht, M. Altorfer, J. A. Robinson, in 'Advances in Medicinal Chemistry', Ed. B. E. Maryanoff, A. B. Reitz, JAI Press, Stamford, Connecticut, 1999, p. 1.

[5] S. J. DeMarco, H. Henze, A. Lederer, K. Moehle, R. Mukherjee, B. Romagnoli, J. A. Robinson, F. Brianza, F. O. Gombert, S. Lociuro, C. Ludin, J. W. Vrijbloed, J. Zumbrunn, J.-P. Obrecht, D. Obrecht, V. Brondani, F. Hamy, T. Klimkait, Bioorg. Med. Chem. 2006, 14, 8396.

[6] a) A. Descours, K. Moehle, A. Renard, J. A. Robinson, Chembiochem 2002, 3, 318; b) R. Fasan, R. L. Dias, K. Moehle, O. Zerbe, D. Obrecht, P. R. Mittl, M. G. Grutter, J. A. Robinson, Chembiochem 2006, 7, 515.

[7] S. M. Foord, T. I. Bonner, R. R. Neubig, E. M. Rosser, J. P. Pin, A. P. Davenport, M. Spedding, A. J. Harmar, Pharmacol. Rev. 2005, 57, 279.

[8] a) A. Muller, B. Homey, H. Soto, N. Ge, D. Catron, M. E. Buchanan, T. McClanahan, E. Murphy, W. Yuan, S. N. Wagner, J. L. Barrera, A. Mohar, E. Verastegui, A. Zlotnik, Nature 2001, 410, 50; b) H. Tamamura, A. Hori, N. Kanzaki, K. Hiramatsu, M. Mizumoto, H. Nakashima, N. Yamamoto, A. Otaka, N. Fujii, FEBS Lett. 2003, 550, 79; c) P. Staller, J. Sulitkova, J. Lisztwan,
H. Moch, E. J. Oakeley, W. Krek, Nature 2003, 425, 307.

[9] G. Alkhatib, C. Combadiere, C. C. Broder, Y. Feng, P. E. Kennedy, P. Murphy, E. A. Berger, Science 1996, 272, 1955.

[10] a) D. J. Chabot, C. C. Broder, J. Biol. Chem. 2000, 275, 23774; b) Y. Feng, C. C. Broder, P. E. Kennedy, E. A. Berger, Science 1996, 272, 872; c) J. P. Moore, M Stevenson, Nat. Rev. Mol. Cell Biol. 2000, $1,40$.

[11] a) C. C. Bleul, M. Farzan, H. Choe, C. Parolin, I. Clark-Lewis, J. Sodroski, T. A. Springer, Nature 1996, 382, 829; b) M Burger, T. Hartmann, M. Krome, J. Rawluk, H. Tamamura, N. Fujii, T. J. Kipps, J. A. Burger, Blood 2005, 106, 1824.

[12] C. W. Hendrix, C. Flexner, R. T. Macfarland, C. Giandomenico, E. J. Fuchs, E. Redpath, G. Bridger, G. W. Henson, Antimicrob. Agents Chemother. 2000, 44, 1667.

[13] T. Miyata, F. Tokunaga, T. Yoneya, K. Yoshikawa, S. Iwanaga, M. Niwa, T. Takao, Y. Shimonishi, J. Biochem. 1989, 106, 663.

[14] a) H. Nakashima, M. Masuda, T. Murakami, Y. Koyanagi, A. Matsumoto, N. Fujii, N. Yamamoto, Antimicrob. Agents Chemother. 1992, 36, 1249; b) M. Masuda, H. Nakashima, T. Ueda, H. Naba, R. Ikoma, A. Otaka, Y. Terakawa, H. Tamamura, T. Ibuka, T. Murakami, Biochem. Biophys. Res. Commun. 1992, 189, 845.

[15] H. Tamamura, M. Kuroda, M. Masuda, A. Otaka, S. Funakoshi, H. Nakashima, N. Yamamoto, M. Waki, A. Matsumoto, J. M. Lancelin, Biochim. Biophys. Acta 1993, 1163, 209.

[16] C. Sune, L. Brennan, D. R. Stover, T. Klimkait, Clin. Microbiol. Infect. 2004, $10,119$. 